\title{
Atmospheric tar balls: aged primary droplets from biomass burning?
}

\author{
A. Tóth ${ }^{1}$, A. Hoffer ${ }^{2}$, I. Nyirố-Kósa ${ }^{2}$, M. Pósfai ${ }^{1}$, and A. Gelencsér ${ }^{1,2}$ \\ ${ }^{1}$ Department of Earth and Environmental Sciences, University of Pannonia, Veszprém, P.O. Box 158, 8201, Hungary \\ ${ }^{2}$ MTA-PE Air Chemistry Research Group, Veszprém, P.O. Box 158, 8201, Hungary
}

Correspondence to: A. Gelencsér (gelencs@almos.uni-pannon.hu)

Received: 4 November 2013 - Published in Atmos. Chem. Phys. Discuss.: 18 December 2013

Revised: 6 May 2014 - Accepted: 27 May 2014 - Published: 2 July 2014

\begin{abstract}
Atmospheric tar balls are particles of special morphology and composition that are fairly abundant in the plumes of biomass smoke. These particles form a specific subset of brown carbon $(\mathrm{BrC})$ which has been shown to play a significant role in atmospheric shortwave absorption and, by extension, climate forcing. Here we suggest that tar balls are produced by the direct emission of liquid tar droplets followed by heat transformation upon biomass burning. For the first time in atmospheric chemistry we generated tar-ball particles from liquid tar obtained previously by dry distillation of wood in an all-glass apparatus in the laboratory with the total exclusion of flame processes. The particles were perfectly spherical with a mean optical diameter of $300 \mathrm{~nm}$, refractory, externally mixed, and homogeneous in the contrast of the transmission electron microscopy (TEM) images. They lacked any graphene-like microstructure and exhibited a mean carbon-to-oxygen ratio of 10. All of the observed characteristics of laboratory-generated particles were very similar to those reported for atmospheric tar-ball particles in the literature, strongly supporting our hypothesis regarding the formation mechanism of atmospheric tar-ball particles.
\end{abstract}

\section{Introduction}

Light absorption by anthropogenic aerosol is getting increasingly important as carbonaceous particulates including black carbon (BC) become more predominant in the chemical composition of tropospheric aerosol. Unlike atmospheric gases $\mathrm{BC}$ is not a single chemical species but a distinct type of carbonaceous material having very strong specific light absorption over the entire solar spectrum (Petzold et al., 2013). Fur- ther common characteristics are its fractal-like chain aggregate structure, high thermal stability, insolubility in any solvents and specific microstructure (ibid.). Some recent studies indicate that $\mathrm{BC}$ has become the second most potent climate forcing agent, accounting for as much as $60 \%$ of the greenhouse absorption of excess carbon dioxide (Ramanathan and Carmichael, 2008). It should be noted, however, that unlike $\mathrm{CO}_{2}$ that absorbs only in the infrared spectral range, atmospheric $\mathrm{BC}$ directly absorbs sunlight (both incoming and reflected) over the entire solar spectrum with an exceptionally high specific efficiency (mass absorption coefficient $>5 \mathrm{~m}^{2} \mathrm{~g}^{-1}$ at $550 \mathrm{~nm}$ ). On a per mass basis BC is 360000-840 000 times more efficient in terms of instantaneous energy absorption than carbon dioxide (Jacobson, 2002), and its 100 year global warming potential (GWP) is 910 (uncertainties $-90 \%+100 \%$ ) (Bond et al., 2013). Contrary to the greenhouse gases, the mass concentrations of $\mathrm{BC}$ exhibit a very inhomogeneous spatio-temporal distribution in the troposphere due to BC's short atmospheric residence time as well as the distribution and variability of its emission sources. Unfortunately, there is no standard method for the atmospheric measurement of $\mathrm{BC}$, optical and thermooptical methods are those that are most frequently used (Andreae and Gelencsér, 2006; Petzold et al., 2013). Due to the combination of different factors the assessment of the global climate forcing of $\mathrm{BC}$ is loaded with very high uncertainty (best estimate $+1.1 \mathrm{~W} \mathrm{~m}^{-2} ; 90 \%$ uncertainty bounds of $+0.27 \mathrm{~W} \mathrm{~m}^{-2}$ to $+2.1 \mathrm{~W} \mathrm{~m}^{-2}$; Bond et al., 2013) .

Quite recently it has been established that a substantial part of the carbonaceous continuum (brown carbon, $\mathrm{BrC}$ ) between pure graphite and non-absorbing organic aerosol contribute significantly to atmospheric light absorption globally 
(Chung et al., 2012). In spite of the fact that most climate models have so far ignored the absorption of $\mathrm{BrC}$, it may contribute by as much as $20 \%$ to the total absorption at $530 \mathrm{~nm}$ (Chung et al., 2012; Liu et al., 2014). This high contribution of $\mathrm{BrC}$ absorption may result in a change of sign in the net top of the atmosphere (TOA) forcing of aerosols (from being reflective to slightly absorbing) over vast regions impacted by biomass smoke (idem). A specific group of atmospheric particles that likely belongs to $\mathrm{BrC}$ regarding its optical properties are tar balls (Alexander et al., 2008), which were first described in biomass smoke plumes (Pósfai et al., 2003,2004 ) with a contribution to particle number as high as $90 \%$, e.g., in aged smoke from smouldering fire or during an active fire season in the western United States (Hand et al., 2005).

Tar balls can be easily recognized using transmission electron microscopy (TEM) by their relatively narrow size range, almost perfectly spherical shape and their chemical composition. In contrast to other spherical aerosol types such as sulphates, the amorphous tar-ball spheres are refractory and do not volatilize under the electron beam. These particles distinctly differ from $\mathrm{BC}$ particles as they have much larger geometric sizes than the nanospheres of $\mathrm{BC}$, they occur externally mixed (i.e., without being coagulated with one another or other particles), and they do not have the internal microstructure of concentrically wrapped, curved graphenelike layers that are typical for BC.

According to electron energy-loss elemental mapping of individual particles, tar balls consist mostly of carbon and oxygen and only traces of sulphur, potassium, chlorine and silicon. These elements are homogeneously distributed over the entire volume of a relatively fresh tar-ball particle. In the literature the $\mathrm{C} / \mathrm{O}$ atomic ratio in atmospheric tar balls varies widely. Several studies established high C/O ratios (7-10) (Pósfai et al., 2003, 2004; Hand et al., 2005; Niemi et al., 2006; Adachi and Buseck, 2011), whereas others found some tar balls with significantly lower $\mathrm{C} / \mathrm{O}$ ratios in the range of 1-2 (Tivanski et al., 2007; China et al., 2013).

It should be stressed that tar-ball particles might undergo aging processes in the atmosphere resulting in a significantly enhanced oxygen ratio in the outermost layer of the particles at a thickness of 30-40 nm (Hand et al., 2005; Tivanski et al., 2007; China et al. 2013). During their long range atmospheric transport tar-ball particles occasionally form aggregates with up to 10 particles, including coagulation with dust particles (Hand et al., 2005; Deboudt et al., 2010).

It was hypothesized that tar-ball particles form in secondary processes from pyrolysis products in the atmosphere (Pósfai et al., 2004). The authors assumed that the low volatility products of biomass pyrolysis undergo polymerization in multiphase reactions resulting in highly refractory carbonaceous particles. Based on the most characteristic features of the relatively fresh tar-ball particles (spherical shape, large size, lack of coagulation, homogeneous composition, lack of internal core and graphene structures, and high $\mathrm{C} / \mathrm{O}$ atomic ratio) we now suggest a direct emission mechanism for the droplets which may then undergo transformation processes. Our hypothesis is that tar balls are ejected upon burning from the pores of plants as liquid tar droplets then undergo chemical transformations that increase their viscosity and solidify them into highly refractory particles, as observed in the atmosphere. Following this hypothesis the objective of our work was to generate pure tar-ball particles from liquid tar-water emulsions in the laboratory, mimicking processes and conditions that may occur during biomass burning with one notable exception: contact with open flames was totally excluded. A secondary goal was to generate pure tar-ball particles for the experimental determination of their optical properties that are relevant in radiative transfer calculations.

\section{Experimental}

The experimental setup, including the dry distillation of wood was intended to simulate the series of processes that may take place during the burning of wood. Liquid tar and water emulsion may form inside the pores of wood by pyrolysis upon burning (simulated by dry distillation), then ejected as small droplets (simulated by bubble bursting) by forces exerted by the evolving gaseous pyrolysis products and partial vaporization of water from the pores. It was observed that free water can explosively vaporize upon fast pyrolysis (Mohan et al., 2006). It is also notable that the sizes of atmospheric tar-ball particles are comparable with those of the internal pores of various woody species (Plötze and Niemz, 2011). The ejected droplets then pass through the glowing (or flaming) zone where they possibly suffer a heat shock (simulated by passing through the heated zone) before they are released into the atmosphere (simulated by the residence in the buffer flask). It should be noted that the produced liquid tar may also suffer an initial heat shock under the conditions of dry distillation. Heat shock may substantially accelerate chemical transformations of the tar and the release of volatile compounds. It should be emphasized that - unlike typical conditions in biomass fires - flame chemistry is totally excluded in the setup as direct contact with flames is completely avoided.

\subsection{Pyrolysis}

Upon biomass burning, pyrolysis occurs in the deeper zones of the pores of the plants in which the oxygen supply becomes limited and the temperature is between $\sim 200$ and $500^{\circ} \mathrm{C}$ (Ohlemiller, 1985; Mohan et al., 2006). We simulated this process by the dry distillation of wood. In our experiments we produced liquid tar by the dry distillation of dry chops of European turkey oak (Quercus cerris) which is one of the most commonly used firewood in Hungary (Hungarian National Food Chain Safety Office, Forestry Directorate, 2013). The water content of the firewood was $7.1 \mathrm{wt} \%$, and 


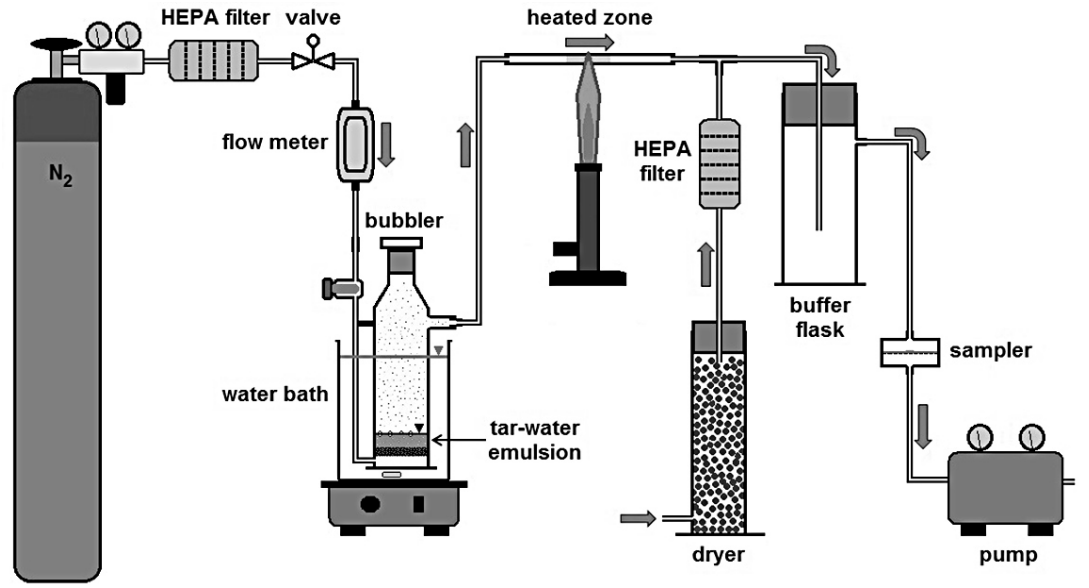

Figure 1. All-glass apparatus for generation and collection of tar-ball particles from liquid tar-water emulsions.

the size of the wood chops was about $25 \times 10 \times 10 \mathrm{~mm}$. About $170 \mathrm{~g}$ of dry chops was subjected to the dry distillation process yielding a liquid tarry condensate of about $40 \mathrm{ml}$. Dry distillation was performed in a long-neck $100 \mathrm{ml} \mathrm{Kjel-}$ dahl flask fixed in a slightly tilted position in order to collect the condensed products at the mouth of the flask. Although the flask was open during the distillation process, there was no contact with the gas flame since the experiment was conducted under a closed hood. The temperature was raised at a rate of about $25^{\circ} \mathrm{C} \mathrm{min}^{-1}$ up to $530^{\circ} \mathrm{C}$ as measured with a thermometer (Testo $925 \mathrm{~K}$-type thermocouple thermometer). Distillation lasted about 20 mins. The products of dry distillation were collected in $40 \mathrm{ml}$ vials, separated into tar and water phases at an approximate volume ratio of $1: 3$. It is well established that a high water yield might cause phase separation (Oasmaa et al., 2010). Precipitation of solids was not observed. Due to their high reactivity and instability the distillation products were used for particle generation within few days after their production.

\subsection{Particle generation and analysis}

A closed all-glass apparatus (Fig. 1) was designed and constructed in which droplets were generated by bubbling purified nitrogen (Messer, purity 99.5\%) through tar-water emulsion $(\sim 1: 1$ volume ratio). The bubbler was a $60 \mathrm{ml}$ peptide synthesis fritted funnel of 10-20 $\mu \mathrm{m}$ porosity (SigmaAldrich Co.) which was held in a water bath at $99^{\circ} \mathrm{C}$. The generated droplets were passed through a glass tube of $200 \mathrm{~mm}$ length ( $12 \mathrm{~mm}$ internal diameter) heated directly with a Bunsen burner from outside. The temperature of the heated zone $\left(30 \mathrm{~mm}\right.$ long) varied between 560 and $630^{\circ} \mathrm{C}$, as measured with a thermometer (Testo $925 \mathrm{~K}$-type thermocouple thermometer). Since the gas flow rate in the tube was $\sim 0.6 \mathrm{~L} \mathrm{~min}{ }^{-1}$, the residence time in the heated zone was about $0.3 \mathrm{~s}$. After the heated zone the nitrogen flow was mixed with dry air at a flow rate of $7.4 \mathrm{~L} \mathrm{~min}^{-1}$, then passed through a buffer volume of $10.75 \mathrm{~L}$ (residence time $1.2 \mathrm{~min}$ ). At the outlet the particles were collected on TEM grids (lacey Formvar/carbon TEM copper grid of 200 mesh, Ted Pella Inc., USA) fixed on $13.1 \mathrm{~mm}$ disks of quartz filters (Whatman QMA) placed into a filter holder (syringe-filter holder). The sampling time was $5 \mathrm{~min}$ in all cases.

Particles were also collected directly at the outlet of the bubbler (without heating) on TEM grids for analysis.

The morphology and elemental composition of the particles were studied in bright-field TEM images obtained using a Philips CM20 TEM operated at $200 \mathrm{kV}$ accelerating voltage. The possible presence of an internal structure was checked in high-resolution electron micrographs. The electron microscope was equipped with an ultra-thin-window Noran Voyager detector that allowed the energy-dispersive $\mathrm{X}$-ray analysis (EDS) of the elemental compositions of individual particles. A dolomite $\left(\mathrm{CaMg}\left(\mathrm{CO}_{3}\right)_{2}\right)$ standard was analyzed to obtain sensitivity factors (" $k$-factors") for the quantitative thin-film analyses of $\mathrm{C}$ and $\mathrm{O}$. Spectra were acquired for $60 \mathrm{~s}$, with the diameter of electron beam adjusted to include the individual tar-ball particles.

\section{Results}

\subsection{Morphology, size and structure of the laboratory- generated particles}

The morphology of the laboratory-generated particles is similar to atmospheric tar-ball particles reported in biomass smoke. In the samples collected directly at the outlet of the bubbler (without applying heat shock) deformed, eggshaped particles were observed besides a few spherical particles (Fig. 2a). These particles were present as both aggregates and individual particles. In some aggregates the interstitial void between the particles was filled with an apparently liquid phase which is presumably the aqueous phase of 

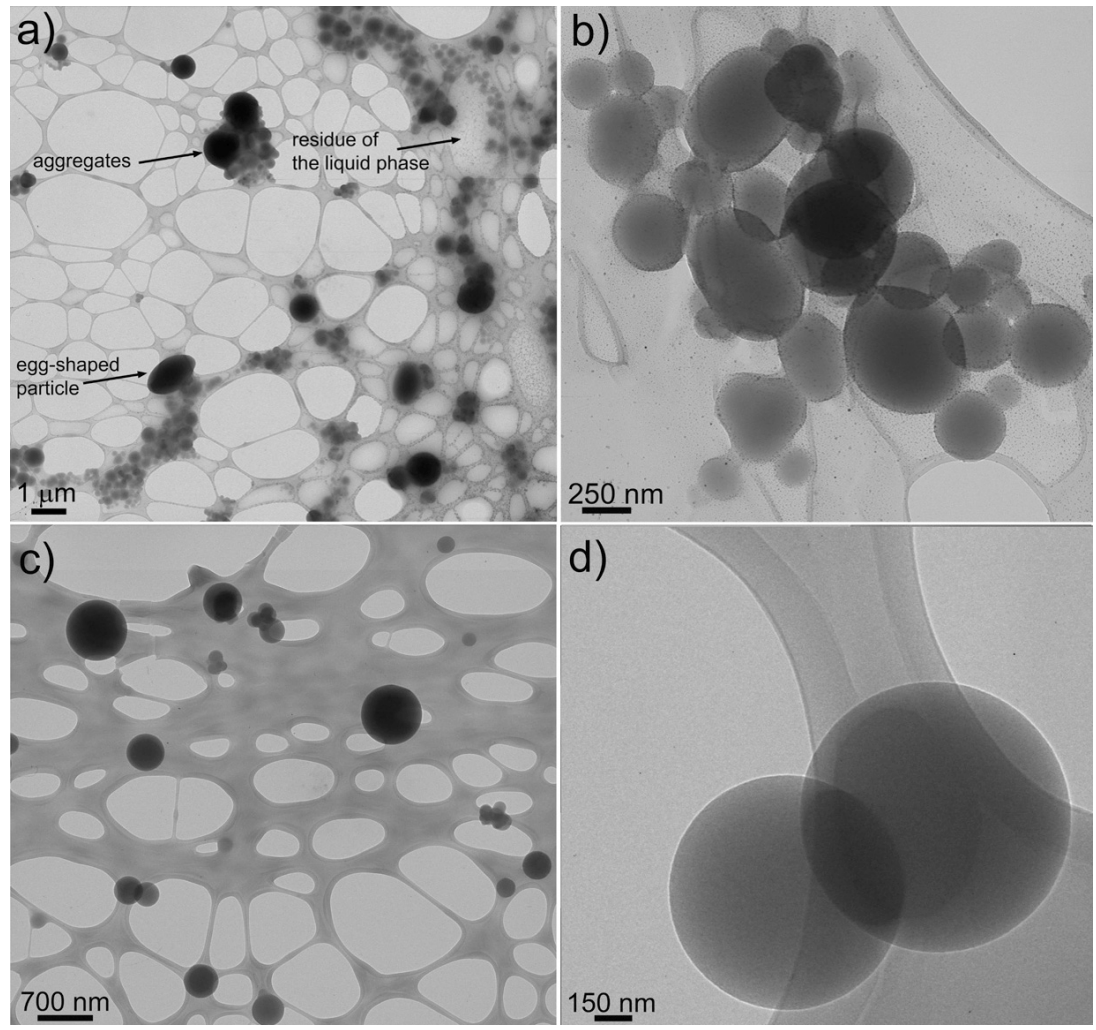

Figure 2. Bright-field TEM images of particles collected after the bubbler (without heating) (a and b) and those collected at the outlet of the apparatus (after heat shock and aging) (c and d).

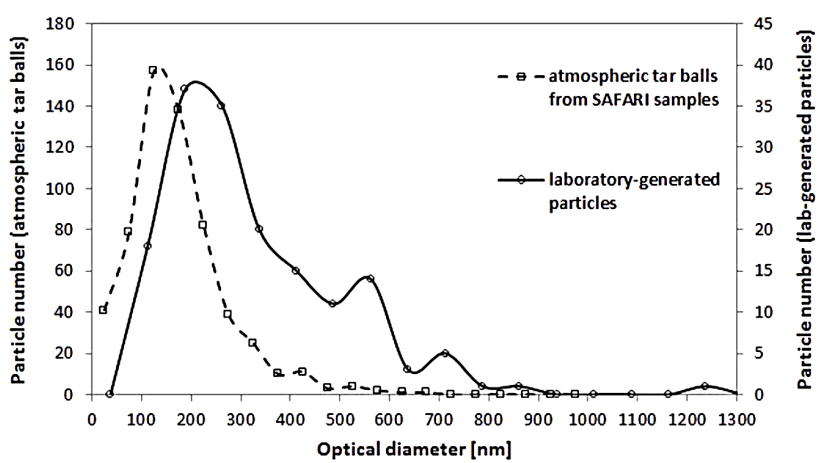

Figure 3. Size distributions of atmospheric tar balls from SAFARI samples (Pósfai et al., 2004) and laboratory-generated particles.

the emulsion (Fig. 2a). The deformed shape of the particles and the presence of a liquid phase indicated that the majority of these particles were liquid tar droplets of varying degree of viscosity. This is not surprising since these droplets were emitted by bubble bursting (direct emission, in analogy with the ejection of droplets from pores).

In contrast to the aerosol samples collected directly after the bubbler, almost only perfectly spherical particles were observed in the samples collected at the outlet of the apparatus. In other terms, particles undergoing a heat shock at $\sim 600^{\circ} \mathrm{C}$ solidified to the extent that they did not spread on the sample grid. The observed size distribution of the in-vacuo optical diameters of the laboratory-generated particles collected on grids is shown in Figure 3, together with those of ambient tar-ball particles determined using the very same method (Pósfai et al., 2004). There is fairly good agreement between the two size distributions, and the mean size $(300 \mathrm{~nm})$ is well within the range reported for atmospheric tar balls (30-500 nm) by others (Pósfai et al., 2003; Fu et al., 2012; Adachi and Buseck, 2011). Similarly to the atmospheric tar-ball particles the laboratory-generated particles did not contain any internal core or a layered microstructure, based on their homogeneous contrast in the bright field TEM image (Fig. 2d).

The "raw" particles collected without a heat shock were mostly liquid droplets whereas those which underwent aging (heat shock at $600{ }^{\circ} \mathrm{C}$ ) were clearly solidified. Tar-ball particles observed in the atmosphere were all solids as seen in their compact spherical morphology that is preserved upon impact on sampling grids. In the burning of biomass, ejected tar droplets cannot escape into the atmosphere without passing through a high temperature zone of variable height and temperature. This fact lends strong support to our experimental approach that uses heat shock to simulate this basic process occurring during biomass burning. Indeed, this 


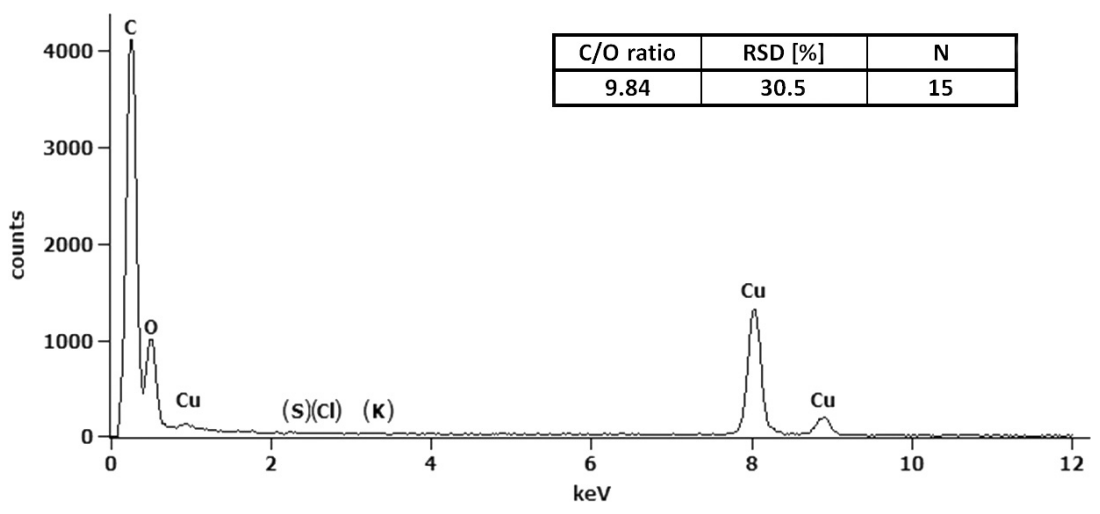

Figure 4. Typical EDS spectrum from a laboratory-generated tar-ball particle and the average $\mathrm{C} / \mathrm{O}$ molar ratio of 15 measured particles. (The copper peaks are artifacts that originate from the supporting grid.)

heat shock was clearly needed to produce rigid spherical particles very similar to atmospheric tar balls. The observed phenomenon, the flash solidification of tar droplets may follow from the ultra-high reactivity of tar constituents which is well-known in tar (or bio-oil) chemistry. The tar (or biooil) is an unstable mixture of a plethora of different chemical compounds. In the overview by $\mathrm{Lu}$ et al. (2009) four stages of the aging of bio-oil were distinguished, associated with fast increase in the viscosity: "thickening, phase separation, gummy formation from the pyrolytic lignins (around $140^{\circ} \mathrm{C}$ ), and char/coke formation from the gummy phase at higher temperatures". It is possibly the last stage of aging that is relevant in both our experiments and in atmospheric tar-ball formation. Unfortunately, no direct justification of this assumption is possible since atmospheric observations of tar balls are concerned only with the "end-products" of formation, whereas experimental observations of tar aging are always performed in bulk. However, there is one indirect implication from a recent study demonstrating that tar can polymerize and form char already inside the pores of the burning biomass at higher temperatures (Pattanotai et al., 2013).

\subsection{Chemical composition of laboratory-generated tar- ball particles}

Figure 4 shows a typical EDS spectrum of a tar-ball particle produced from thermally aged tar droplets. Some of these particles contained other elements $(\mathrm{K}, \mathrm{S}, \mathrm{Si})$ at most in trace amounts if at all, which is consistent with previous observations of atmospheric tar-ball particles (Pósfai et al., 2003; Pósfai et al., 2004; Adachi and Buseck, 2011; Niemi et al., 2006). The carbon-to-oxygen ratios of the tar-ball particles after thermal shocking are listed in Table 1 . The $\mathrm{C} / \mathrm{O}$ ratios varied between 6 and 18, the average was about 10 . The carbon-to-oxygen ratios of liquid tar droplets and aggregates were found to be much more variable and spatially inhomogeneous ranging from close to one (hydrocarbon-like species) up to the high bound value of solid tar-ball particles.
Table 1. Carbon and oxygen atomic content of laboratory-generated tar balls measured with TEM/EDS.

\begin{tabular}{llll}
\hline & Carbon [\%]: & Oxygen [\%]: & C/O ratio: \\
\hline 1 & 91 & 8.6 & 10 \\
2 & 90 & 9.4 & 9.7 \\
3 & 90 & 9.7 & 9.3 \\
4 & 95 & 5.2 & 18 \\
$5^{*}$ & 93 & 7.0 & 13 \\
6 & 90 & 9.7 & 9.3 \\
7 & 89 & 11 & 8.2 \\
8 & 92 & 7.6 & 12 \\
9 & 90 & 10 & 8.6 \\
10 & 91 & 8.7 & 10 \\
11 & 88 & 12 & 7.0 \\
12 & 90 & 9.4 & 9.7 \\
13 & 87 & 13 & 6.4 \\
$14 * *$ & 86 & 14 & 6.0 \\
$15^{*}$ & 90 & 10 & 8.8 \\
Average: & $90 \%$ & $9.8 \%$ & 9.8 \\
RSD: & $2.6 \%$ & $24 \%$ & $30 \%$ \\
\hline
\end{tabular}

* Traces of potassium detected.

** Traces of potassium and chlorine detected.

This is possibly due to phase separation processes such as volatilization and condensation as well as the variable water content of the droplets formed from aqueous emulsion.

It should be noted that the elemental composition of tarball particles might depend on many factors, including the type of the burned biomass and the conditions of burning. Furthermore, most methods used for the determination of elemental abundances in individual particles are semiquantitative only, thus they involve significant uncertainties. Nevertheless, the EDS spectra of the tar balls generated in our experiments are very similar to those reported for atmospheric tar-ball particles (Adachi and Buseck, 2011). 


\section{Conclusions}

For the first time perfectly spherical carbonaceous particles very similar to atmospheric tar balls in all of their observed properties were produced in the laboratory with the total exclusion of flame processes. All of the characteristic features (perfectly spherical shape, size range, lack of coagulation, lack of internal structure, homogeneous composition, high $\mathrm{C} / \mathrm{O}$ atomic ratio) of laboratory-generated particles match those observed in atmospheric tar-ball particles. Based on these findings and the initial assumptions it can be hypothesized that tar-ball particles may indeed form by the ejection of liquid tar droplets (pyrolysis products of biomass burning) from the pores of the burning biomass, followed by rapid thermal transformation upon passing through the flame or glow zone of the fire. In the light of atmospheric observations of tar-ball particles it can be added that flame chemistry in the fire zone or multiphase chemical reactions in the smoke plume may also contribute to the aging (charring/solidification) of the ejected tar droplets. The experimental setup that was used in this study has the further advantage that pure tar-ball particles can be generated for the direct experimental determination of atmospherically relevant optical properties of this important subset of light-absorbing carbonaceous (brown carbon) particles. However, in order to better understand the complex processes of tar ball formation further studies are clearly warranted.

Acknowledgements. This research was realized in the frames of TÁMOP 4.2.4.A/2-11-1-2012-0001 "National Excellence Program - Elaborating and operating an inland student and researcher personal support system". The project was subsidized by the European Union and co-financed by the European Social Fund. We thank the colleagues of the Botanical Garden of the University of West Hungary for providing the biomass used in the experiments.

Edited by: A. Kiendler-Scharr

\section{References}

Adachi, K. and Buseck, P. R.: Atmospheric tar balls from biomass burning in Mexico, J. Geophys. Res.-Atmos., 116, D05204, doi:10.1029/2010JD015102, 2011.

Alexander, D. T. L., Crozier, P. A., and Anderson, J. R.: Brown carbon spheres in East Asian outflow and their optical properties, Science, 321, 833-835, doi:10.1126/science.1155296, 2008.

Andreae, M. O. and Gelencsér, A.: Black carbon or brown carbon? The nature of light-absorbing carbonaceous aerosols, Atmos. Chem. Phys., 6, 3131-3148, doi:10.5194/acp-6-3131-2006, 2006.

Bond, T. C., Doherty, S. J., Fahey, D. W., Forster, P. M., Berntsen, T., DeAngelo, B. J., Flanner, M. G., Ghan, S., Kärcher, B., Koch, D., Kinne, S., Kondo, Y., Quinn, P. K., Sarofim, M. C., Schultz, M. G., Schulz, M., Venkataraman, C., Zhang, H., Zhang, S., Bellouin, N., Guttikunda, S. K., Hopke, P. K., Jacobson, M. Z., Kaiser, J.W., Klimont, Z., Lohmann, U., Schwarz,
J. P., Shindell, D., Storelvmo, T., Warren, S. G., and Zender, C. S.: Bounding the role of black carbon in the climate system: A scientific assessment, J. Geophys. Res., 118, 5380-5552, doi:10.1002/jgrd.50171, 2013.

China, S., Mazzoleni, C., Gorkowski, K., Aiken, A. C., and Dubey, M. K.: Morphology and mixing state of individual freshly emitted wildfire carbonaceous particles, Nature Comm., 4, 2122, doi:10.1038/ncomms3122, 2013.

Chung, C. E., Ramanathan, V., and Decremer, D.: Observationally constrained estimates of carbonaceous aerosol radiative forcing, Proc. Natl. Acad. Sci. USA, 109, 11624-11629, doi:10.1073/pnas.1203707109, 2012.

Deboudt, K., Flament, P., Choel, M., Gloter, A., Sobanska, S., and Colliex, C.: Mixing state of aerosols and direct observation of carbonaceous and marine coatings on African dust by individual particle analysis, J. Geophys. Res.-Atmos., 115, D24207, doi:10.1029/2010JD013921, 2010.

Fu, H., Zhang, M., Li, W., Chen, J., Wang, L., Quan, X., and Wang W.: Morphology, composition and mixing state of individual carbonaceous aerosol in urban Shanghai, Atmos. Chem. Phys., 12, 693-707, doi:10.5194/acp-12-693-2012, 2012.

Hand, J. L., Malm, W. C., Laskin, A., Day, D., Lee, T., Wang, C., Carrico, C., Carrillo, J., Cowin, J. P., Collet, Jr., J., and Iedema, M. J.: Optical, physical and chemical properties of tar balls observed during the Yosemite Aerosol Characterisation Study, J. Geophys. Res.-Atmos., 110, D21210, doi:10.1029/2004JD005728, 2005.

Hungarian National Food Chain Safety Office, Forestry Directorate: (National Statistical Data Collection Program) OSAP 1254, OSAP 1257 and OSAP 1260, Budapest, 2013.

Jacobson, M. Z.: Control of fossil-fuel particulate black carbon and organic matter, possibly the most effective method of slowing global warming, J. Geophys. Res., 107, 4410, doi:10.1029/2001JD001376, 2002.

Liu, J., Scheuer, E., Dibb, E., Ziemba, L. D., Thornhill, K. L., Anderson, B. E., Wisthaler, A., Mikoviny, T., Devi, J. J., Bergin, M., and Weber, R. J.: Brown carbon in the continental troposphere, Geophys. Res. Lett., 41, 2191-2195, doi:10.1002/2013GL058976, 2014.

Lu, Q., Li, W. Z., and Zhu, X. F.: Overview of fuel properties of biomass fast pyrolysis oils, Energ. Convers. Manage., 50, 13761383, doi:10.1016/j.enconman.2009.01.001, 2009.

Mohan, D., Pittman, Jr., C. U., and Steele, P. H.: Pyrolysis of Wood/Biomass for Bio-oil: A Critical Review, Energ. Fuels, 20, 848-889, doi:10.1021/ef0502397, 2006.

Niemi, J. V., Saarikoski, S., Tervahattu, H., Mäkelä, T., Hillamo, R., Vehkamäki, H., Sogacheva, L. and Kulmala M.: Changes in background aerosol composition in Finland during polluted and clean periods studied by TEM/EDX individual particle analysis, Atmos. Chem. Phys., 6, 5049-5066, doi:10.5194/acp-6-50492006, 2006.

Oasmaa, A. and Peacocke, C.: Properties and fuel use of biomassderived fast pyrolysis liquids, A guide, in: VTT Publications, 731, VTT Technical Research Centre of Finland, Espoo, Finland, $1-125,2010$.

Ohlemiller, T. J.: Modeling of smoldering combustion propagation, Prog. Energ. Combust., 11, 277-310, doi:10.1016/03601285(85)90004-8, 1985. 
Pattanotai, T., Watanabe, H., and Okazaki, K.: Experimental investigation of intraparticle secondary reactions of tar during wood pyrolysis, Fuel, 104, 468-475, doi:10.1016/j.fuel.2012.08.047, 2013.

Petzold, A., Ogren, J. A., Fiebig, M., Laj, P., Li, S.-M., Baltensperger, U., Holzer-Popp, T., Kinne, S., Pappalardo, G., Sugimoto, N., Wehrli, C., Wiedensohler, A., and Zhang, X.-Y.: Recommendations for reporting "black carbon" measurements, Atmos. Chem. Phys., 13, 8365-8379, doi:10.5194/acp-13-83652013, 2013.

Plötze, M. and Niemz, P.: Porosity and pore size distribution of different wood types as determined by mercury intrusion porosimetry, Europ. J. Wood Wood Prod., 69, 649-657, doi:10.1007/s00107-010-0504-0, 2011.

Pósfai, M., Simonics, R., Li, J., Hobbs, P. V., and Buseck, P. R.: Individual aerosol particles from biomass burning in southern Africa, 1, Compositions and size distributions of carbonaceous particles, J. Geophys. Res.-Atmos., 108, 8483, doi:10.1029/2002JD002291, 2003.
Pósfai, M., Gelencsér, A., Simonics, R., Arató, K., Li, J., Hobbs, P. V., and Buseck, P. R.: Atmospheric tar balls: Particles from biomass and biofuel burning, J. Geophys. Res.-Atmos., 109, D06213, doi:10.1029/2003JD004169, 2004.

Ramanathan, V. and Carmichael, G.: Global and regional climate changes due to black carbon, Nat. Geosci., 1, 221-227, doi:10.1038/ngeo156, 2008.

Tivanski, A. V., Hopkins, R. J., Tyliszczak, T., Gilles, M. K.: Oxygenated interface on biomass burn tar balls determined by single particle scanning transmission X-ray microscopy, J. Phys. Chem. A, 111, 5448-5458, doi:10.1021/jp070155u, 2007. 